\section{Discordant effects of rasagiline doses in Parkinson disease}

\section{Spyros N. Deftereos and Christos A. Andronis}

We read with interest the News \& Views article by Sampaio et al. (Parkinson disease: ADAGIO trial hints that rasagiline slows disease progression. Nat. Rev. Neurol. 6, 126-128; 2010). ${ }^{1}$ The authors conclude that although the net benefit that rasagiline is able to deliver is what is really relevant for an individual patient's wellbeing, understanding the diseasemodifying effects of the drug has much to offer to the scientific community and to society at large. We agree with their view and we believe that elucidating the discordant neuroprotective effects of the $1 \mathrm{mg} /$ day and $2 \mathrm{mg} /$ day doses of rasagiline remains important, in view of the continuing scientific debate on the topic. ${ }^{2}$

The authors of the ADAGIO study found the fact that the higher dose of rasagiline did not confer a stronger neuroprotective effect than the lower dose difficult to explain and proposed that a marked effect of the higher dose on symptoms might have masked a benefit associated with early-start treatment in patients with very mild disease. ${ }^{2,3}$ However, rasagiline has several mechanisms of action in addition to monoamine oxidase type B inhibition, which makes alternative explanations possible. In particular, rasagiline has been reported to induce the anti-apoptotic protein $\mathrm{Bcl}-2$ at $10 \mathrm{nM}$ to $10 \mu \mathrm{M}$ and
$10-100 \mathrm{pM}$ but not outside these ranges, and to upregulate glial cell line-derived neurotrophic factor (GDNF) at $100 \mathrm{nM}^{2,4}$ Considering that the maximum plasma concentrations after repeated dosing with $1 \mathrm{mg} /$ day or $2 \mathrm{mg} /$ day are $8.5 \pm 2.2 \mathrm{ng} / \mathrm{ml}$ $(31.7 \pm 8.2 \mathrm{nM})$ and $14.9 \pm 10.5 \mathrm{ng} / \mathrm{ml}$ $(=55.7 \pm 39.2 \mathrm{nM})$, respectively, ${ }^{5}$ the higher dose would be expected to exert a more potent neuroprotective effect than the lower one, contrary to the observed clinical results. Therefore, rasagiline neuroprotection is unlikely to be mediated solely by upregulation of GDNF or Bcl-2.

Recently, rasagiline has been shown to inhibit glyceraldehyde-3-phosphate dehydrogenase (GAPDH), an enzyme that catalyzes the sixth step of glycolysis and participates in the initiation of apoptosis. ${ }^{6}$ Under oxidative stress, GAPDH is inactivated, causing a switch of glucose metabolism to the pentose phosphate pathway. This increases the production of NADPH, which is required for the recycling of glutathione. Inhibition of GAPDH, therefore, enhances the antioxidant defenses of dopaminergic cells, and protects them from apoptosis. However, by inhibiting glycolysis, the drug also deprives cells of much-needed energy. We propose that the balance between enhancement of the anti-apoptotic/ antioxidant effects and inhibition of the glycolytic actions of GAPDH by rasagiline may contribute towards determining its overall effects. Stronger inhibition of glycolysis at $2 \mathrm{mg} /$ day might outweigh other benefits, causing reduced clinical efficacy. We believe that additional studies are warranted to examine this hypothesis, which might help elucidate the puzzling effects of rasagiline.

Biovista Inc., 927 Raymond Road, Charlottesville, VA 22902, USA

(S. N. Deftereos, C. A. Andronis).

Correspondence to: S. N. Deftereos s.deftereos@biovista.com

\section{doi:10.1038/nrneurol.2010.2-c1}

\section{Competing interests}

The authors declare no competing interests.

1. Sampaio, C. \& Ferreira, J. J. Parkinson disease: ADAGIO trial hints that rasagiline slows disease progression. Nat. Rev. Neurol. 6, 126-128 (2010).

2. Youdim, M. B. Rasagiline in Parkinson's disease. N. Engl. J. Med. 362, 657-658 (2010).

3. Olanow, C. W. et al. ADAGIO Study Investigators. A double-blind, delayed-start trial of rasagiline in Parkinson's disease. N. Engl. J. Med. 361, 1268-1278 (2009).

4. Blandini, F., Armentero, M. T., Fancellu, R., Blaugrund, E. \& Nappi, G. Neuroprotective effect of rasagiline in a rodent model of Parkinson's disease. Exp. Neurol. 187, 455-459 (2004).

5. Rabey, J. M. et al. Rasagiline Study Group. Rasagiline mesylate, a new MAO-B inhibitor for the treatment of Parkinson's disease: a doubleblind study as adjunctive therapy to levodopa. Clin. Neuropharmacol. 23, 324-330 (2000).

6. Ou, X. M. et al. Glyceraldehyde-3-phosphate dehydrogenase-monoamine oxidase B-mediated cell death-induced by ethanol is prevented by rasagiline and 1-R-aminoindan. Neurotox. Res. 16, 148-159 (2009). 